
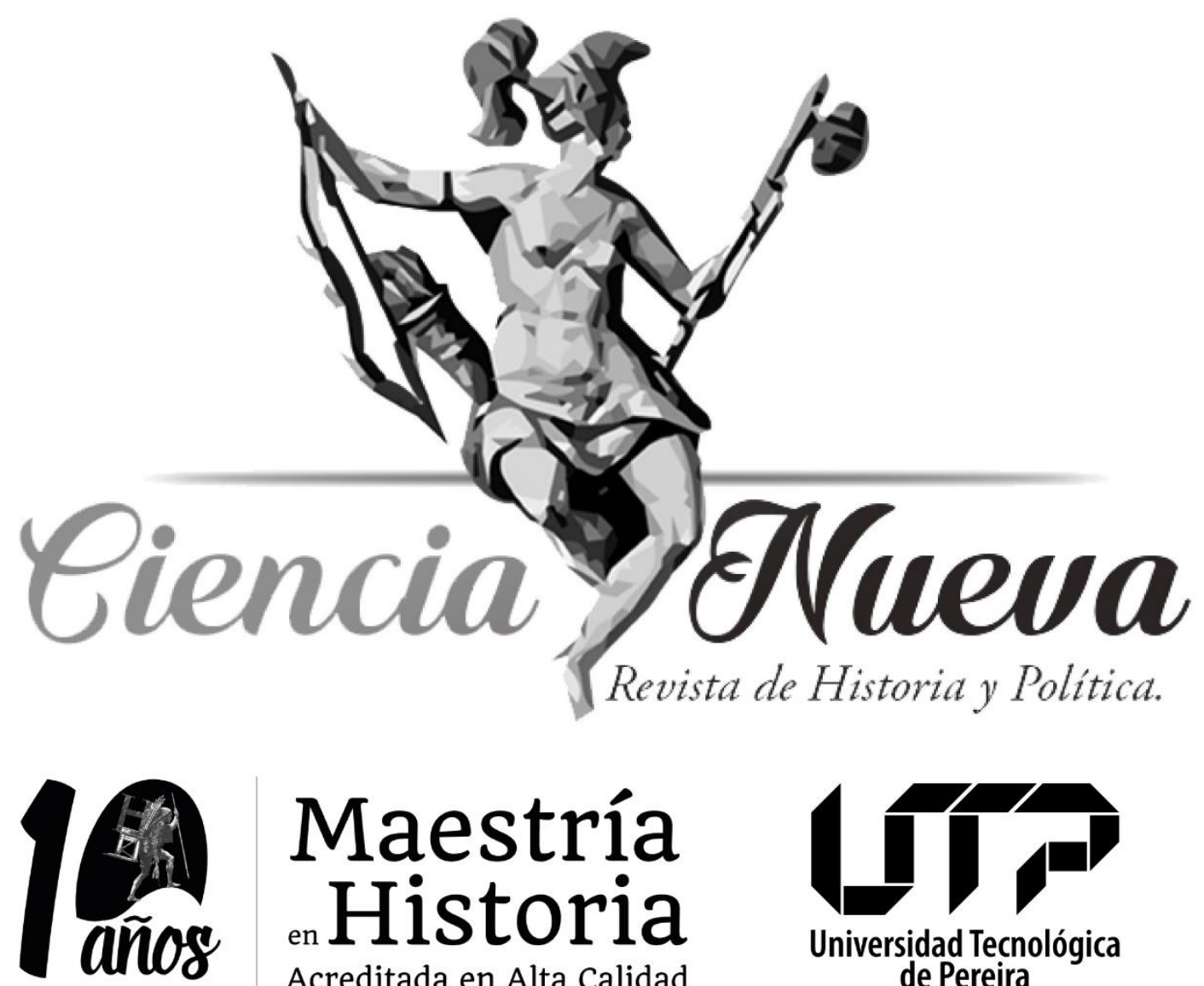

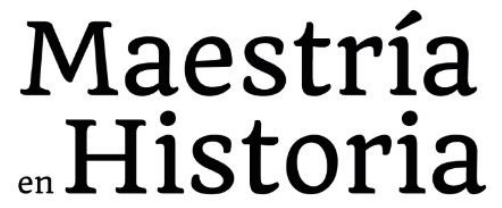

Acreditada en Alta Calidad

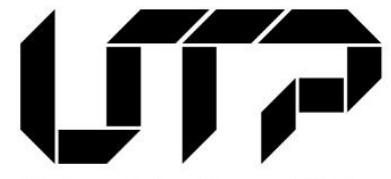

Universidad Tecnológica de Pereira

DEMOCRACIA DELEGATIVA EN EL SIGLO XXI: UNA APROXIMACIÓN A LAS PRESIDENCIAS DE ÁLVARO URIBE

VÉLEZ (2002-2010)

DELEGATIVE DEMOCRACY IN THE 21ST CENTURY: AN APPROACH TO THE PRESIDENCES OF

ÁLVARO URIBE VÉLEZ (2002-2010)

Flavio Costa

pp. $46-70$

DOI: https://doi.org/10.22517/25392662.21121

Vol. 4 Núm. 2 | Julio-diciembre de 2020

Pereira, Colombia

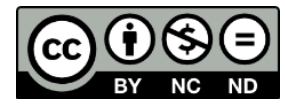




\title{
DEMOCRACIA DELEGATIVA EN EL SIGLO XXI: UNA APROXIMACIÓN A LAS PRESIDENCIAS DE ÁlVARo URIBE VÉLEZ (2002-2010) *
}

\author{
DELEGATIVE DEMOCRACY IN THE 21ST CENTURY: AN APPROACH TO THE \\ PRESIDENCES OF ÁlVARO URIBE VÉLEZ (2002-2010)
}

\author{
Flavio Costa ${ }^{* *}$ \\ costaflavio184@gmail.com
}

ORCID: http://orcid.org/0000-0002-2394-9337

\begin{aligned} & \hline Recibido: 27 de febrero de 2019. \\ & Revisado: 13 de septiembre de 2019. \\ & Aceptado: 22 de septiembre de 2020. \\ & Publicado: 31 de diciembre de 2020. \\ & \hline\end{aligned}

\section{Resumen}

En el presente trabajo me propongo indagar acerca de la concepción y el ejercicio del poder por parte de Álvaro Uribe Vélez como presidente de Colombia (2002-2010). Para ello me sirvo del concepto acuñado por el politólogo Guillermo O'Donnell, democracia delegativa. Bajo la peculiar tipificación que este tipo de democracia ofrece, recorro la emergencia de Uribe como presidente de Colombia y el tipo de liderazgo ejercido durante sus mandatos. Además, analizo el vínculo del líder con las instituciones horizontales de control y rendición de cuentas. El objetivo del artículo es advertir la presencia o ausencia de ciertas dimensiones planteadas en el cuerpo teórico O'Donneleano durante las presidencias de Álvaro Uribe.

Palabras clave: democracia delegativa, O'Donnell, Colombia, Álvaro Uribe Vélez, Liderazgo, institucionalidad, rendición de cuentas.

\begin{abstract}
In the present work I investigate about the conception and exercise of power by Alvaro Uribe Vélez as president of Colombia (2002-2010). For this I use the concept coined by political scientist Guillermo O'Donnell, delegative democracy. Under the peculiar typification that this type of democracy offers, I trace the emergence of Uribe as president of Colombia and the type of leadership exercised his term. In addition, I analyze the link of the leader with the horizontal institutions of control and accountability. The objective of the article is to warn the presence or absence of certain dimensions raised in the O'Donneleano theoretical body during the presidencies of Álvaro Uribe.
\end{abstract}

Keywords: Delegative democracy, O'Donnell, Colombia, Álvaro Uribe, leadership, institutionality, accountability.

\section{Introducción}

El politólogo Guillermo O'Donnell, fue uno de los intelectuales que se dio a la tarea de explorar las democracias latinoamericanas modernas atendiendo las singularidades que

\footnotetext{
* Este documento respeta las directrices y normas dispuestas en la Declaración de Ética de Publicación de Ciencia Nueva, Revista de Historia y Política. Esta declaración puede consultarse en la página web de la revista: http://revistas.utp.edu.co/index.php/historia

** Magister en Historia por la Universidad Nacional de Tres de Febrero (UNTREF), Buenos Aires, Argentina.
} 
ellas presentan. Para ello, el autor realizó un análisis comparado entre las democracias originarias del cuadrante noroccidente ${ }^{1}$ y las democracias latinoamericanas. Esta perspectiva comparada le permitió identificar varias digresiones que explican la substancia de estas últimas, dejando a su paso una enriquecedora caja de herramientas conceptuales. En ella podemos encontrar definiciones, tales como zonas marrones, ciudadanía de baja intensidad, Accountability horizontal débil o intermitente y democracia delegativa (DD). Esta última tipología política acuñada por O'Donnell a comienzos de los años ' $90^{2}$, será retomada en el presente artículo con el objeto de acercarnos a los gobiernos de Álvaro Uribe Vélez (2002 a 2010) en Colombia.

Luego de recorrer la transición desde los regímenes autoritarios latinoamericanos de 1960-19803 con su obra "Transitions from Authoritrian Rule: Prospects for Democracy", coeditada con Philippe Schmitter y Laurence Whitehead ${ }^{4}$, O'Donnell se propone indagar acerca de la calidad democrática de estos nuevos gobiernos y regímenes del postautoritarismo. Su principal inquietud radicaba en construir una teoría democrática que atendiera las particularidades de los países latinoamericanos a partir de una definición multinivel de la democracia política: el nivel estatal, el nivel del régimen y el nivel de la ciudadanía 5 .

De esta manera, al explorar las características de los procesos de democratización política en Latinoamérica que tanto lo inquietaban, el autor encuentra que los líderes gubernamentales de países como Argentina, Brasil o Perú son poseedores del derecho, delegado por el electorado, de gobernar como mejor les parece. Además, son hostiles a los patrones de representación normales de una democracia representativa y a toda clase de "responsabilidad horizontal". A estos tipos de democracias política, débilmente institucionalizadas, O'Donnell las define, en contraste con las democracias representativas, democracia delegativa (en adelante DD). Este neologismo fue utilizado por el autor para dar

\footnotetext{
${ }^{1}$ Este término refiere a las democracias de Estados Unidos de América, de Europa Occidental — principalmente de Francia e Inglaterra - y de Nueva Zelanda y Australia.

${ }^{2}$ El texto original fue publicado en portugués en octubre de 1991 en la revista Novos estudos del CEBRAP de San Pablo. En 1992 fue publicado en español en los Cuadernos del CLAHE en la ciudad de Montevideo y en 1994 en inglés, en el Journal of Democracy.

3 "Los regímenes autoritarios se hicieron presentes durante esos años en la mayoría de los países sudamericanos. En Argentina desde 1966 a 1973 y luego de 1976 a 1983; en Brasil desde el golpe a João Goulart en 1964 hasta 1985; en Chile el régimen cívico militar encabezado por Augusto Pinochet se extendió de 1973 a 1990 ; en Bolivia los gobiernos militares se desarrollaron entre 1964 y 1982; en Paraguay la dictadura de Stroessner inició en 1954 y se prolongó hasta el inicio de 1989; en Perú los gobiernos militares ocuparon el poder desde 1968 a 1980; en Uruguay la dictadura cívico militar se extendió de 1973 a 1985. Las excepciones a estos regímenes autoritarios se dieron en países como Colombia y Venezuela donde, sin embargo, se tejieron acuerdos frentistas entre los principales partidos políticos los cuales se alternaban el poder con el objeto de disminuir el clima de violencia política. En Colombia, se celebró en 1957, el Frente Nacional entre conservadores y liberales. En Venezuela, el Pacto de Punto Fijo realizado en 1958 entre el AD, Copei y URD". Flavio Costa, "Democracia delegativa de alta intensidad: una mirada sobre el régimen político argentino del siglo XXI”, Ciencia Nueva. Revista de Historia y Política 2, n. ${ }^{\circ} 1$ (2018), 76.

${ }^{4}$ Guillermo O'Donnell, Philippe Schmitter y Laurence Whitehead (ed.), Transitions from Authoritrian Rule: Prospects for democracy (Baltimore/London: University Press, 1986).

${ }^{5}$ Guillermo O'Donnell, Democracia, agencia y estado (Buenos Aires: Prometeo Libros, 2010).

${ }^{6}$ Guillermo O'Donnell, “¿Democracia Delegativa?”, Cuadernos del CLAEH 17, n. ${ }^{\circ} 61$ (1992): 9-19.
} 
cuenta de "un nuevo animal" con características suficientemente particulares como para analizarlo diferencialmente respecto a otros modelos políticos.

Con el paso de los años, ciertos trazos característicos de esta "nueva criatura política" bautizada como DD, emergieron en varios regímenes latinoamericanos, e incluso en ciertas democracias de Europa del Este y Asia. Ello trajo aparejado una interesante apuesta intelectual que desbordó las fronteras originales para las cuales fue creada la definición me refiero a los gobiernos de Carlos Menem en Argentina, Fernando Collor en Brasil y la primera presidencia de Alan García en Perú-. El resultado de esta apuesta fue una copiosa bibliografía en torno a los diferentes tópicos que conforman una DD teniendo en cuenta los causes de la política en América Latina y otras partes del mundo ${ }^{7}$.

Luego, animado por la vigencia y la expansión del concepto, O'Donnell reflexionó acerca del mismo, a la luz de nuevos acontecimientos políticos, sociales y económicos acaecidos en la región. Ello dio origen a una definición conceptual revisada que permitió advertir que determinadas características de las DD pervivieron en varios regímenes políticos latinoamericanos de principios de este $\operatorname{siglo}^{8}$. Dicha revisión teórica me permite reflexionar acerca de las dinámicas propias de este tipo de democracias y sus apariciones o ausencias durante los mandatos de Álvaro Uribe Vélez en Colombia (2002 a 2010).

Así es como, para el desarrollo del presente trabajo, voy a plantear ciertas líneas de investigación que me conduzcan a transitar estas agitadas aguas de la política colombiana a partir del bagaje conceptual presente en un tipo de DD. En ese sentido, mencionaré algunas características genéricas que presenta esta tipología, teniendo en cuenta el instrumental teórico O'Donnelleano. Luego, me propongo reflexionar respecto a la génesis del uribismo al calor de una crisis sociopolítica generalizada, para continuar el análisis sobre el vínculo entre el líder y la ciudadanía política. Finalmente, me permito indagar acerca del

\footnotetext{
${ }^{7}$ Varios países de la región, tanto a nivel nacional como subregional, han sido analizados por diversos autores a partir del concepto de democracia delegativa: para el caso de Colombia, Mauricio Uribe López, "Colombia y Venezuela: ¿democracias delegativas o autoritarismos competitivos?” Nueva Sociedad 227 (2010): 20-30. Carlos Pérez Múnera, "La democracia delegativa", Revista Facultad de Derecho y Ciencias Políticas 37, n. '106 (2007): 263-289. Para Argentina, Osvaldo Iazzeta. "La democracia delegativa y su cara estatal. Un abordaje del caso argentino”, en Democracia delegativa, coord. por Guillermo O’Donnell, Osvaldo Iazzeta y Hugo Quiroga (Buenos Aires: Prometeo Libros, 2011), 79-114. Hugo Quiroga, "Parecidos de familia. La democracia delegativa y el decisionismo democrático", en Democracia delegativa, coord. por Guillermo O’Donnell, Osvaldo Iazzeta y Hugo Quiroga (Buenos Aires: Prometeo Libros, 2011), 35-52. María Ollier, "Centralidad presidencial y debilidad institucional en las democracias delegativas", en Democracia delegativa, coord. por Guillermo O’Donnell, Osvaldo Iazzeta y Hugo Quiroga (Buenos Aires: Prometeo Libros, 2011), 115-137. Gabriela Ippolito-O'Donnell, "Visiones ciudadanas en torno de la democracia delegativa: Argentina y Brasil" en Democracia delegativa, coordinado por Guillermo O'Donnell, Osvaldo Iazzeta y Hugo Quiroga (Buenos Aires: Prometeo Libros, 2011), 53-78. Para México, Emmerich (2009) y Olvera (2011). Para Ecuador, Mejía Acosta (2011). Para Nicaragua, Anderson (2006). Para Venezuela, Uribe López, "Colombia y Venezuela: ¿democracias delegativas o autoritarismos competitivos?”. Para América Central, en general, Walker (2009). Algunos trabajos que podemos mencionar por fuera del contorno latinoamericano son: para Filipinas, Croissant (2003). Para Ucrania, Kubicek (1994, 2000). Para Kazajistán, Kubicek (1998). Para Rusia, Hale y McFaul (2004), Brown (1999), Shevtsova (1999), Tsygankov (1998) y Kubicek (1994).

${ }^{8}$ Guillermo O'Donnell, "Nuevas reflexiones acerca de la democracia delegativa (DD)", en Democracia delegativa, coord. por Guillermo O’Donnell, Osvaldo Iazzeta y Hugo Quiroga (Buenos Aires: Prometeo Libros, 2011), 19-32.
} 
funcionamiento de los mecanismos de accountability horizontal durante los gobiernos del expresidente Álvaro Uribe.

No quisiera concluir esta introducción sin advertir que el presente trabajo no pretende agotar el tema ni mucho menos, sino plantear algunos lineamientos generales y preliminares que me sirvan de base para ahondar, a través de estudios futuros, en el análisis de la democracia en Colombia.

\section{Un tipo de democracia unanimista, con fuerte liderazgo y débil institucionalidad}

O'Donnell señala que la democracia delegativa es una forma de concepción y ejercicio del poder que se aparta de las concepciones del régimen democrático representativo. ${ }^{9}$ De alguna manera, el politólogo argentino observa que a partir de las décadas de 1980 y 1990, gran parte de las democracias Latinoamericanas no adoptan la forma de regímenes democráticos representativos (la excepciones son Uruguay, Costa Rica y, con algunos matices, Chile). Es decir, comienza un proceso de mutación del régimen político representativo que trae aparejada una desafección de la ciudadanía que va más allá de los dirigentes o los partidos políticos y alcanza a todo el andamiaje institucional en general. A la despartidización de la política debemos sumar que, para gran parte de la comunidad política, la institucionalización tradicional comienza a ser vista como un obstáculo para modificar el statu quo ${ }^{10}$

Sin embargo, en este tipo de democracia delegativa hay una ausencia de participación ciudadana activa involucrada en la responsabilidad de controlar a quienes toman decisiones de políticas públicas y en ellas la figura del líder político (principalmente el presidente de la Nación) encarna y representa los intereses de la patria ${ }^{11}$

Entonces, en lugar de que una nueva institucionalidad inclusiva y abarcativa reemplace a la institucionalidad tradicional, los regímenes democráticos se van deslizando hacia un movimiento presidencialista. Ello se explica porque la elección popular de los cargos del Ejecutivo se ha convertido en un factor central en la organización política de los pueblos $^{12}$. Así es como, los presidentes elegidos, no se conciben como sucesores en el liderazgo del espacio político que representan, sino como padres fundadores de una gesta que transformará el curso de la historia nacional. Sin embargo, cabe señalar que ello no implica un ejercicio de poder absolutamente omnipotente o de legibus solutus por parte del presidente.

\footnotetext{
9 Guillermo O'Donnell, "Nuevas reflexiones acerca de la democracia delegativa (DD)", en Democracia delegativa, Guillermo O’Donnel, Osvaldo Iazzetta y Hugo Quiroga (Compiladores), (Buenos Aires: Prometeo, 2011).

${ }^{10}$ Isidoro Cheresky, El Nuevo Rostro de la Democracia, (Buenos Aires: Fondo de Cultura Económica), 81 y 82.

${ }^{11}$ Quiroga, "Parecidos de familia. La democracia delegativa y el decisionismo democrático", en Democracia delegativa, Guillermo O’Donnel, Osvaldo Iazzetta y Hugo Quiroga (Compiladores), (Buenos Aires: Prometeo, 2011), 45.

12 Pierre Rosanvallon, El buen gobierno (Buenos Aires: Ediciones Manantial, 2015), 16 y 17.
} 
Bajo estas nociones e instrumentos teóricos, a continuación, nos proponemos un estudio de aproximación a las características a nivel del régimen de las presidencias de Álvaro Uribe Vélez.

\section{Del contexto socio político durante la era preuribista}

Recordemos que, en una DD, el líder emerge bajo una severa crisis generalizada que puede responder a varios factores -por ejemplo, el principal factor en Colombia fue la escalada del conflicto armado interno-, donde está en juego el sistema de subsistencia de las relaciones sociales. Por eso, me resulta ineludible realizar un breve repaso de la situación sociopolítica colombiana de fines del siglo XX que derivó en el contexto de crisis generalizada en el que Álvaro Uribe asume la presidencia en 2002.

Hacia mediado de los ochenta, Colombia emprende un camino de transición política hacía un régimen democrático inclusivo dejando atrás definitivamente, un pacto entre las fuerzas políticas tradicionales que dio origen al Frente Nacional ${ }^{13}$. El entonces presidente Virgilio Barco asume su mandato en 1986 y decide gobernar en exclusividad con su propia fuerza política sin otorgar ninguna concesión a sus rivales políticos. Concurrentemente, se comienza a gestar un clima social de fuerte cuestionamiento sobre los partidos políticos tradicionales y las instituciones representativas en general. La sensación en gran parte de la ciudadanía era que estas instituciones políticas no los representaban por tratarse de espacios limitados a las disputas entre las elites. ${ }^{14}$

Ante la falta de empatía que despertaba la política en gran parte de la sociedad colombiana, representantes de diferentes ámbitos de la comunidad como la universidad, la iglesia, los sindicatos y las propias instituciones estatales; consideraron imprescindible iniciar un proceso de transformación del estado con miras a democratizar y modernizar la política en el país. En esa dirección, se convoca a una Asamblea Constituyente elegida popularmente a fines de 1990, con el objetivo de reformar la Constitución Nacional vigente.

El nuevo marco normativo surgido de las discusiones dadas en las mesas de debates, buscó prioritariamente ampliar el juego de la representatividad política a sectores de la sociedad históricamente marginados. Es decir, fue una oportunidad propicia para democratizar el régimen político logrando elecciones transparentes, competitivas e

\footnotetext{
${ }^{13}$ A diferencia de la mayoría de los países de la región que fueran víctimas de golpes de estado entre los años 1960-1980, en Colombia se realiza un plebiscito a fines de 1957 que da origen a un pacto entre las fuerzas políticas tradicionales liberales y conservadoras. Este acuerdo consistía en que ambas fuerzas se alternarían el poder político a lo largo de 16 años a través de la construcción binaria del gabinete. Con esta decisión se pretendía, principalmente, traer cierto alivio a un clima de violencia marcado por las luchas sectarias entre liberales y conservadores, etapa de la historia de Colombia que se la conoce como los años de La Violencia. Estos temas han despertado un gran interés en buena parte de la intelectualidad colombiana de los últimos años: por ejemplo, Sánchez y Peñaranda (1996). Sin embargo, sigue siendo una referencia ineludible el clásico trabajo de Guzmán, Fals Borda y Umaña Luna La violencia en Colombia (Bogotá, 1962).

${ }^{14}$ Francisco Leal Buitrago, "Democracia oligárquica y rearticulación de la sociedad civil: El caso colombiano", en Transición y Perspectivas de la Democracia en Iberoamérica, Pensamiento Iberoamericano: Revista de Economía Política (14), (Madrid: Siglo XXI España Editores, 1988), 54 a 58.
} 
igualitarias ${ }^{15}$. En segundo lugar, incorporó al ordenamiento jurídico nuevos derechos humanos y ecológicos, así como también, el reconocimiento de la pluralidad étnica colombiana. Además, se instauraron nuevas figuras institucionales que pretendieron fortalecer la independencia del Poder Judicial y empoderar a la ciudadanía a través del control constitucional y la tutela. Esto último permitió, avanzar en muchos derechos laborales e individuales de ciertas minorías históricamente discriminadas. ${ }^{16}$

Sin embargo, más allá de las reformas institucionales de 1991, Colombia no logró revertir en la práctica, la debilidad política, civil y social de su sistema democrático. La brecha que separaba la efectividad de la legalidad estatal entre territorios, categorías sociales y grupos culturales continuaba incólume. Así pues, la falta de un sistema legal extendido que sancionara, promulgara y respaldara a un conjunto de derechos civiles, políticos y sociales básicos; generaba que no pocos territorios estuvieran fuera del alcance del estado, conformándose lo que O'Donnell denominó, zonas marrones. Estas zonas, por definición, cuentan con una baja o nula presencia del estado, tanto desde la eficacia institucional como desde el punto de vista legal. ${ }^{17}$

Estas características convirtieron a dichos territorios en lugares atractivos para la instalación de grupos armados ilegales. Ellos iban ocupando discrecionalmente los espacios que el estado no lograba tapizar con su presencia ${ }^{18}$. A ello habría que sumar la extensión en las fuentes de financiamiento de estos grupos ilegales a partir del auge del narcotráfico y la actividad petrolera. Sin duda, esto último contribuyó a la propagación de la actividad armada ilegal en las últimas décadas ${ }^{19}$.

\footnotetext{
${ }^{15}$ Como señala Ricardo Arias Trujillo, el mejor ejemplo de ello lo constituyó la propia elección para conformar la Asamblea Nacional Constituyente. Allí, el M-19, grupo guerrillero recientemente desmovilizado, obtuvo casi un $27 \%$ de los votos detrás del liberalismo, pero superando al Partido Conservador. Asimismo, también hubo espacio para minorías religiosas y étnicas, para grupos sindicales y nuevas fuerzas sociales (Arias Trujillo 2010, 170 y 171).

${ }^{16}$ Marco Palacios y Frank Safford, Historia de Colombia: País fragmentado, sociedad dividida, (Bogotá: Ediciones Uniandes, 2002), 467.

17 Guillermo O’Donnell, Acerca del estado, la democratización y algunos problemas conceptuales: Una perspectiva latinoamericana con referencia a países poscomunistas, (Buenos Aires: Desarrollo Económico (130), 1993), 169 y 170.

${ }^{18}$ Luis J. Orjuela Escobar afirma que el estado colombiano había reducido su capacidad para mediar y canalizar los conflictos o tensiones sociales, lo que causó expresiones de "parainstitucionalidad” (Orjuela Escobar 2000, 104). En ese sentido, prefiero hablar del estado como ordenador de relaciones sociales y no como árbitro o mediador de conflictos. Además, creo que esta característica del estado colombiano no es un fenómeno nuevo y exclusivo, sino histórico y compartido por la mayoría de las democracias latinoamericanas.

${ }^{19}$ El crecimiento de cultivos de uso ilícitos fue directamente proporcional al crecimiento de los miembros que conformaban los grupos armados. Las áreas cultivadas con plantas de coca alcanzaron una extensión inédita de casi 140.000 mil hectáreas durante los años 2001/2002 y los grupos armados FARC, AUC y ELN, hacía el año 2000, seguían incrementando el número de miembros incorporados a sus filas -se calcula que el primero contaba con más de 16000 miembros, el segundo más de 8000 y el tercero más de 4000-. Por otra parte, las zonas de producción petrolera han sido uno de los blancos preferidos de las FARC y el ELN a la hora de buscar fuentes de financiamiento. Los grupos guerrilleros, a través del sabotaje o la coerción sobre gobiernos locales y empresas productoras, lograron obtener un porcentaje de las regalías petroleras y hacerse de parte de los impuestos a los recursos hidrocarburíferos. (Guáqueta 2003, 26-30)
} 
La expansión de los grupos armados ilegales extendió la violencia e incrementó el número de desplazados en el país -por ejemplo, más de 400.000 personas debieron desplazarse forzosamente durante el año 2002-. Las poblaciones campesinas debían migrar de sus territorios de origen, por la violación sistemática de sus derechos humanos más elementales. Amenazas, intentos de homicidios, homicidios, desapariciones o torturas y reclutamientos forzados eran los principales motivos de estos desplazamientos según los datos de la Encuesta Nacional de Hogares Desplazados (ENHD) de $2004 .^{20}$

Pensemos únicamente, en la cantidad de derechos vulnerados a la población civil durante una posesión violenta e ilegal de tierras o al controlar una pequeña población emplazada en áreas rurales. Es decir, varios de los derechos humanos básicos listados por la Organización de las Naciones Unidas (ONU) como el derecho a la vida, a la libertad, a la seguridad, a la libre circulación, a la elección libre de residencia, a la propiedad individual o colectiva, entre otros, se ven violentados ante el avance de estos grupos armados ilegales sobre la población civil (“Declaración Universal de los Derechos Humanos”).

Además, en los puntos geográficos distantes de los centros urbanos o en las periferias de las grandes ciudades -donde por lo general arribaban los grupos desplazados de áreas rurales-, las propias leyes vigentes eran aplicadas de manera intermitente según el grupo social o étnico al que pertenecía el ciudadano afectado $^{21}$; y los grupos de instituciones o agencias estatales, corrompían el poder público al tejer vínculos con poderes que llevaban a cabo actividades ilícitas.

Así mismo, en la aplicación intermitente de las leyes formales se infiltraban la aplicación de leyes informales dictadas arbitrariamente por grupos con intereses particulares. Este estado legal débil o inexistente reprodujo, e incluso, extendió relaciones sociales y de poder desparejas. Al mismo tiempo, como explica O'Donnell para la realidad latinoamericana en general, la aplicación discrecional de la ley formal, en intermitencia con la aplicación de la ley informal, requiere de un aparato coercitivo violento que infunda miedo en la población civil. $^{22}$

De ahí se explican, en parte, los vínculos entre grupos armados ilegales y actores del sistema político legal, por cierto, largamente extendidos en la realidad colombiana. Ambos habían entablado nexos que reportaban mutuos beneficios en temas tales como, el cobro de un porcentaje del impuesto municipal por parte de los grupos armados ilegales a cambio de garantizar un territorio libre de contrincantes políticos o la imbricación de ambos sectores con el tráfico de drogas ilícitas como fuente de financiamiento. Estos últimos, son solo dos

\footnotetext{
${ }^{20}$ Ana Ibañez y Andrea Velásquez, El impacto del desplazamiento forzoso en Colombia: condiciones socioeconómicas de la población desplazada, vinculación a los mercados laborales y políticas públicas, (Santiago de Chile: CEPAL-Serie Políticas sociales -145-, 2004), 14 y 15.

${ }^{21}$ Por ejemplo, el acceso a los tribunales de justicia se torna dificultoso para quienes se encuentran en situación de vulnerabilidad social. Mientras que, aquellos que ocupan un lugar privilegiado socialmente, no solo acceden a los tribunales de justicia, sino que su situación económica le permite contratar abogados prestigiosos o peritos de parte y no pocas veces, pagar algún tipo de soborno en la justicia para evitar la condena.

${ }^{22}$ Guillermo O’Donnell, Disonancias: Críticas democráticas a la democracia, (Buenos Aires: Prometeo Libros, 2007), 164.
} 
ejemplos de innumerables situaciones donde la ilegalidad penetró en el sistema político ${ }^{23}$. Asimismo, estos vínculos permitieron a los grupos armados ilegales o narcotraficantes buscar atajos de negociación con el poder central que los blindara de cierta legitimidad, ausente ante la sociedad por las continuas prácticas de secuestros o extorsión sobre la población civil. ${ }^{24}$

En un escenario de violencia creciente, hacia finales de la década de 1990 las negociaciones de paz con el grupo guerrillero FARC en el Caguán, impulsadas por el entonces presidente Andrés Pastrana (1998 a 2002), habían arrojado escasos resultados en materia humanitaria. El grupo guerrillero logró el control de $42.000 \mathrm{~km} 2$ ampliando sus nexos con el narcotráfico y trasladando a buena parte de los ciudadanos secuestrados a esa zona despejada. Es decir, los acuerdos lejos de lograr alcanzar la paz tan ansiada, acentuaron un conflicto armado repudiado por la mayoría de los colombianos, que se sentían ajenos a los intereses o dinámicas propias que estos iban tomando. La falta de identificación política, ideológica y cultural de la población con los actores armados, llevó a estos últimos a exigir lealtad a los primeros bajo amenaza o coerción, colonizando aquellos derechos civiles que el estado de derecho podía asegurar a sus ciudadanos. ${ }^{25}$

Este estado de cosas propició un clima de temor generalizado en la ciudadanía que observaba impávida la expansión de la violencia armada hacia los grandes conglomerados urbanos. La falta de seguridad ciudadana -por cierto, ampliamente extendida en esos añosse convirtió en la base discursiva fundamental sobre la que Álvaro Uribe cimentó su popularidad, a partir de un tono fuertemente cuestionador de los procesos de paz propuestos por su antecesor. Así pues, ante la falta de respuesta por parte del sistema democrático representativo para resolver los conflictos armados de décadas, gran parte de los colombianos demandaban una fuerza política superior que ponga fin a ese estado de caos e inseguridad intensificado en los últimos años. ${ }^{26}$

Al mismo tiempo, continuaba la descomposición de las viejas maquinarias de los partidos tradicionales lo que dio paso a una creciente fragmentación política donde la disputa entre candidatos se imponía por sobre la disputa política partidaria. Esta creciente atomización de los partidos políticos dio origen a las "Microempresas Electorales" donde los

\footnotetext{
${ }^{23}$ Los objetivos y métodos que utilizaron los diferentes grupos armados para capturar la representación política, es un tema que ha sido ampliamente cubierto por diferentes autores colombianos. Algunos de estos trabajos son: Francisco Gutiérrez Saín, Ilegalidad y sistema político en Colombia: la agenda de Uribe Vélez, 2004, Nueva Sociedad $N^{\circ}$ 192; Francisco Gutiérrez Saín, Politicians and Criminals: Two Decades of Turbulence, 1978-1998, International journal of politics, culture and society, vol. 14, $\mathrm{N}^{\circ}$ 1, 2000, PP. 71-87; Mauricio Romero, Paramilitares y Autodefensas, 1983.2003, Iepri/Planeta, Bogotá, 2002; Claudia López, La refundación de la Patria, de la teoría a la evidencia, Debate, Bogotá, 2010, pp. 29-78; Miriam Álvaro Rodriguez, LA PARAPOLÍTICA: La infiltración paramilitar en la clase política colombiana, año 15, número 24, enero-julio 2008, Universidad Autónoma de Manizales; Ariel Fernando Ávila y Juan David Velasco, Parapolíticos, narcos, guerrilleros y votos: revisando el problema de la teoría democrática a partir del caso colombiano, vol 17, No 2, Pap. Político Bogotá (Colombia), 2012, pp. 371-421.

${ }^{24}$ Eric Lair, Colombia: Una guerra contra los civiles. (Bogotá: Colombia Internacional 49-50, 2000$), 141$.

25 Ibid., 144 y 145.

${ }^{26}$ Mauricio Uribe López, Colombia y Venezuela: ¿democracias delegativas o autoritarismos competitivos?, (Nueva Sociedad 227, 2010), 27.
} 
partidos, movimientos o coaliciones presentaban múltiples listas en las distintas jurisdicciones electorales haciendo un culto al personalismo. ${ }^{27}$

En ese contexto, los partidos políticos tradicionales dejaron de funcionar como factor exclusivo de articulación política de la sociedad, dando paso a una nueva cultura política menos programática y más pragmática. Es decir, la composición del sistema político se desliza desde las plataformas políticas de adscripción tradicional liberal y conservadora, hacia un conjunto de agrupaciones que ingresaron en la arena política para ganarse el favor de los electores.

En ese sentido, se observó una reconfiguración en el enraizamiento de los partidos políticos colombianos en la sociedad. El electorado en su mayoría, ya no poseía la tradicional identificación partidista lo que entrañaba un comportamiento volátil en sus preferencias políticas. Esta conducta respondía a la falta de confianza de la sociedad en los partidos políticos por el incumplimiento -o el cumplimiento parcial- de las responsabilidades asignadas por el sistema legal al cargo gubernamental. Este incumplimiento se materializaba, por ejemplo, en vínculos de la clase política con actores del crimen organizado, recurrente casos de corrupción y la propia ineficacia como instancia de representación de los intereses ciudadanos. $^{28}$

Así es como, la situación de inseguridad generalizada y la crisis del estado y la política tradicional, confluyeron para generar una gran insatisfacción y falta de apoyo de los colombianos a la democracia representativa como sistema político ${ }^{29}$. Esto factores podrían explicar en gran medida, el encumbramiento de un líder de centro derecha en el escenario político colombiano, cuyo lema de campaña era actuar con "mano firme y corazón abierto".

\section{El ascenso de Álvaro Uribe a la presidencia: Un estilo personalista en el ejercicio del poder}

En orden a lo explicado anteriormente, Álvaro Uribe Vélez, un outsider de la política tradicional que representaba al movimiento independiente Primero Colombia - el cual aglutinaba a listas pertenecientes a diferentes fuerzas políticas-, alcanza la presidencia obteniendo el 53,05\% de los votos y venciendo al candidato por el Partido Liberal Horacio Serpa.

Durante su discurso de inicio del primer mandato, el flamante presidente convocó a retomar el lazo de confianza de los ciudadanos hacia el estado y señaló que "el desproporcionado apego al interés propio e indiferencia por la suerte de la comunidad" se explica por "la violencia destructora, la politiquería y la corrupción que concurren a la

\footnotetext{
${ }^{27}$ Eduardo Pizarro Leongómez, La Atomización Partidista en Colombia: el fenómeno de las Micro-empresas electorales, (EEUU: Kellog Intitute -292-, 2002), 16 a 20.

${ }^{28}$ Javier Duque Daza, Partidos y partidismo. Los partidos políticos colombianos y su enraizamiento en la sociedad, (Revista FACULTAD DE DERECHO Y CIENCIAS POLÍTICAS -120-, 2014), 344 y 345.

${ }^{29}$ Según Latinobarómetro en el año 2001 solo el 22\% de los colombianos se encontraba satisfecho y daba apoyo a la democracia como sistema político ubicándose en el último lugar entre los países latinoamericanos encuestados ("Latinobarómetro") Fuente: www.latinobarometro.org/LATBD_latinobarometro_Informe_2001.
} 
incertidumbre, la miseria y la desigualdad" 30 De su propia estrategia discursiva que buscaba diferenciarse de la "politiquería y la corrupción", radica la importancia de presentarse como un outsider incontaminado de las prácticas políticas clientelares y corruptas ${ }^{31}$.

El sentido de sus discursos conjuntamente con sus primeras decisiones en el poder, daban cuenta de la intención de Álvaro Uribe de buscar reconstruir las identidades políticas sobre la base de un vínculo vertical directo entre el líder y la ciudadanía. Esta concepción del ejercicio del poder comienza a perfilarse desde el inicio mismo de su gestión. La creación de los Consejos Comunales de Gobierno, son un buen ejemplo de ello ${ }^{32}$. Estos mecanismos verticales permitieron al entonces presidente de Colombia, en determinadas ocasiones, saltar espacios de intermediación política cómo el Congreso, los partidos políticos, las gobernaciones o las alcaldías. Al igual que otros líderes políticos contemporáneos, el entonces presidente de Colombia alcanzó un gran reconocimiento ciudadano a partir de su perfil comunicacional y sus acciones públicas; reprodujo su adhesión popular hacia su figura por el vínculo directo con la ciudadanía; en sus discursos hablaba en primera persona y más allá de representar a un determinado espacio político, su reconocimiento no derivaba de dicha representación sino del ejercicio del "liderazgo de popularidad". 33

La forma omnipresente de ejercer el poder que exhibía Álvaro Uribe, conducía a sus seguidores a pensar que su figura resultaba imprescindible para lograr el tan ansiado bienestar general. Por más nimio que fuera el problema, la figura del líder político estaba presente pasando por alto las distintas esferas intermedias de gobierno. Así pues, sus simpatizantes colocaban los atributos personales del presidente por encima de una plataforma de gobierno que se destaque por su solidez programática. Ya el primer referendo presentado por Álvaro Uribe ante el Congreso a fines de $2002^{34}$, fue planteado por sus seguidores como un plebiscito de apoyo al líder, exacerbando el clima unanimista imperante. ${ }^{35}$

Por otro lado, debido a la coyuntura crítica que atravesaba el país en materia de seguridad, los principales objetivos del gobierno de Álvaro Uribe fueron el fortalecimiento del estado y la recuperación de los territorios que se encontraban bajo el dominio de los grupos armados ilegales. Para ello impulsó, durante su primer mandato -2002 a 2006-, la denominada Política de Seguridad Democrática, construida sobre tres líneas concurrentes

\footnotetext{
${ }^{30}$ Discurso de posesión del presidente Álvaro Uribe Vélez. 2002. El Tiempo, 8 de agosto.

31 Por ejemplo, durante los años 90 hubo 41 acusaciones penales a los congresistas por vínculos con el narcotráfico, 17 por crímenes contra la administración pública y 9 por peculado (Gutiérrez Sanín 2004, 71)

${ }^{32}$ Estos Consejos Comunales de Gobierno iniciaron en agosto de 2002 cuando el presidente Álvaro Uribe organizó el evento en Pasto, Nariño. Estos permitían entablar un vínculo directo entre el presidente y los ciudadanos salteando etapas de intermediación política. En total, durante los mandatos de Álvaro Uribe, se celebraron más de 300 eventos resultando una de las estrategias comunicacionales más eficiente de su administración ("Los consejos comunales" 2010).

${ }^{33}$ Isidoro Cheresky, El nuevo rostro de la democracia, (Buenos Aires: Fondo de Cultura Económica, 2015), 106.

34 Este referendo conformado por un texto de 17 preguntas dirigidas a la ciudadanía formaba parte de una Gran Reforma política que buscó modificar una serie de artículos constitucionales (Sánchez 2002).

${ }^{35}$ Alejo Vargas Velásquez, El gobierno de Álvaro Uribe: proyecto y resultados, (Nueva Sociedad -192-, 2005), 93.
} 
pero al mismo tiempo contradictorias: la continuación de la ofensiva armada contra el grupo guerrillero FARC iniciada por su antecesor Andrés Pastrana, una política de desmovilización pacífica de los grupos paramilitares ${ }^{36} \mathrm{y}$, con relación a las dos anteriores, un conjunto de políticas de seguridad particulares como la militarización de los campesinos y la redes de informantes. ${ }^{37}$

Durante esos años no pocos espacios en manos de la guerrilla fueron recuperados por la fuerza pública y el nivel de secuestros y delitos perpetrados por las FARC disminuyó considerablemente. Sin embargo, al tratarse de un enfoque eminentemente militar, carecía de una mirada integral del conflicto que contemplara dimensiones tan o más importantes que la militar, como la civil o la social.

En ese sentido, el estatus de policía judicial otorgado excepcionalmente a las fuerzas militares y la limitación a los derechos civiles esenciales de las poblaciones afectadas por la presencia guerrillera, debilitó -o desmontó- un conjunto de derechos y/o capacidades que resultan imprescindibles en una democracia. Ello se resume en la propuesta de Álvaro Uribe de "menos libertades y más seguridad", juridificado a través del llamado "estatuto antiterrorista" ${ }^{38}$ Reducir la seguridad en un régimen democrático al accionar de la fuerza pública frente al delito violento resulta, al menos, una definición minimalista de la propia democracia. Garantizar seguridad a los ciudadanos en una democracia implica, entre otras cosas, lograr que estos gocen y ejerzan con libertad un conjunto de derechos y capacidades mínimas sin ningún tipo de discriminación por clase social, grupo étnico, lugar geográfico, etc. ${ }^{39}$.

Con todo, la sensación generalizada era que el estado en particular y la política en general, habían recuperado la iniciativa y el control perdido unos años antes. Esto allanó el camino para que una gran cantidad de colombianos pensara que Álvaro Uribe debía gobernar el país durante muchos años, con la esperanza de lograr conducir a Colombia hacia el camino del orden y la calma definitiva. Así pues, por iniciativa de sus seguidores y a instancias de lo dictaminado por el Congreso de la Nación y la Corte, se reformó la Constitución de 1991 autorizándolo a ejercer un segundo mandato consecutivo de cuatro años. Para ello resultó fundamental la imagen positiva del líder ante la opinión pública reflejada en las encuestas y las negociaciones llevadas a cabo por el grupo uribista en el Congreso. Curiosamente, la

\footnotetext{
36 En este sentido, la Ley 975 de 2005 que materializó el proyecto de justicia y paz frente a los grupos paramilitares desmovilizados desde fines de 2002, fue un punto de inflexión para quienes cuestionaban la laxitud de las penas. Incluso para Estados Unidos que, desde los atentados a los Torres Gemelas en septiembre de 2001, había incluido al grupo de las AUC dentro de las organizaciones terroristas.

${ }^{37}$ Francisco Leal Buitrago, La política de seguridad democrática 2002-2005, (Bogotá: Análisis político -57-, 2006), 5 a 7.

${ }^{38}$ Francisco Gutiérrez Sanín, Ilegalidad y sistema político en Colombia: la agenda de Uribe Vélez, (Bogotá: Nueva Sociedad -192-, 2004), 61.

${ }^{39}$ Para este punto resulta interesante el concepto de seguridad democrática en Atehortúa, 2007.
} 
politiquería tan criticada por Álvaro Uribe, hizo lo suyo para lograr alcanzar los objetivos políticos del presidente y sus seguidores ${ }^{40}$.

De esta manera, la función de los partidos políticos se limitó aún más ante "la figura de un presidente convencido de su papel providencial de derrotar a una subversión más arraigada de lo que esperaba y a un informe grupo de políticos sin anclaje partidista"41 Álvaro Uribe dio continuidad a sus políticas públicas de seguridad creando el plan de la Política de Consolidación de la Seguridad Democrática, a partir del inicio de su segundo mandato ${ }^{42}$. Esta permanencia en lo más alto del Poder Ejecutivo, le permitió construir todo un andamiaje político alrededor de su figura con altos índices de popularidad, que dio lugar a la consolidación del uribismo en el poder público colombiano. Así pues, el presidente Uribe y sus principales colaboradores erigieron un régimen altamente personalista donde la única fuente y lugar de autoridad era el Poder Ejecutivo. Además, esta forma de concebir y ejercer el poder era altamente compartida por un sector muy amplio de la población.

Hay otro factor que acerca a las presidencias de Álvaro Uribe con el concepto de DD. Este es que la política en Colombia comenzó a ser permeada por un clima dicotómico entre los simpatizantes de Álvaro Uribe y sus detractores. Los primeros destacaban los logros en la seguridad democrática, la mejora en la economía del país y la alta adhesión popular al líder político. Los segundos alertaban acerca de la creciente concentración del poder, el manejo del presupuesto y la irrupción de un clima social polarizado en torno a la figura del presidente. Esta creciente polarización se pudo haber generado por varios factores que fui repasando a lo largo del capítulo. En primer lugar, la fuerte personalidad del líder con su omnipresencia a cuestas, desencadenó un clima de amor/odio en torno a su figura. Un segundo factor se puede encontrar en la forma directa en que Álvaro Uribe ejercía el poder pasando por alto los espacios de intermediación política. Finalmente, la postura ambigua del entonces presidente con relación a los diferentes grupos armados hizo lo suyo al penetrar en la ejecución de sus programas de seguridad democrática ${ }^{43}$.

Sin embargo, cabe señalar que, a diferencia de otros presidentes latinoamericanos contemporáneos cuyos discursos tendían a dividir la sociedad entre pueblo/elite,

\footnotetext{
${ }^{40}$ Uno de estos actos de corrupción fue destapado cuando la ex representante a la Cámara Yidis Medina admitió haber recibido prebendas políticas por parte de funcionarios nacionales e incluso del propio Álvaro Uribe, a cambio de su apoyo al proyecto de reelección presidencial ("Yidispolítica', el escándalo que nos dejó” 2015).

${ }^{41}$ Francisco Leal Buitrago, La política de seguridad democrática 2002-2005, (Bogotá: Análisis político -57-, 2006), 18

42 Para un balance de la Política de Consolidación de la Seguridad Democrática durante sus primeros años, véase (Atehortúa/Rojas Rivera, 2009).

43 Álvaro Uribe impulsó durante 2005 la ley $\mathrm{N}^{\circ} 975$ de "justicia y paz" aplicable a los paramilitares desmovilizados que no se había acogido a leyes anteriores por ser responsables de graves violaciones de derechos humanos o infracciones al derecho internacional humanitario. Dicha ley preveía beneficios jurídicos para los desmovilizados que incluso podían llegar hasta el indulto. Asimismo, a fines de 2005 el gobierno contempló la posibilidad de iniciar diálogos de paz con el Ejército de Liberación Nacional (ELN). En diciembre se realizó el primer encuentro de representantes del gobierno y ese grupo armado. Sin embargo, en el mismo año las fuerzas militares continuaban con la ofensiva militar contra la retaguardia de las Fuerzas Armadas Revolucionarias de Colombia-Ejército del Pueblo (FARC-EP), principalmente en el sur del país, iniciadas un año antes.
} 
patria/antipatria o amigos/enemigos, el entonces presidente de Colombia utilizaba en sus discursos un tono más conciliador e inclusivo ${ }^{44}$. Es decir, Álvaro Uribe convocaba al esfuerzo y el apoyo de todos los colombianos evitando dirigirse, únicamente, a los representantes del "verdadero pueblo de la nación". Tal vez, ello haya contribuido a no generar una polarización absoluta en la sociedad -con escaso margen para encontrar espacios de convergencia entre rivales políticos- como en otros países de la región.

\section{La relación con los otros poderes del Estado}

Según O'Donnell, una de las características fundamentales de un tipo de DD es la intermitencia y debilidad en la aplicación de los mecanismos del accountability horizontal ${ }^{45}$. Este tópico es sumamente importante dentro de una democracia porque nos habla de la presencia -o la ausencia- de una red de instituciones estatales que tienen el poder legal de, y están fácticamente dispuestas para, sancionar acciones u omisiones de otras instituciones del estado que pueden ser consideradas como ilícitas. Obsérvese que dichas acciones u omisiones pueden significar la transgresión por parte de instituciones estatales, directamente o a través de actores privados, de libertades o garantías liberales - o derechos humanos- como la inviolabilidad del domicilio, la propiedad privada, el derecho a la vida, el derecho a todas las personas de un juicio justo e imparcial y varias más. Además, pueden transgredir las fronteras republicanas al no sujetarse a la ley y dar clara prioridad al interés público por sobre el privado. ${ }^{46}$ En Colombia, veremos que la faceta institucional que protege el republicanismo funciona aceptablemente más allá de presentar ciertas intermitencias.

La Asamblea Constituyente de 1990 dio origen a una Constitución que sitúa a las instituciones en una suerte de profundización democrática. Como vimos anteriormente, el objetivo fue dar un salto de calidad político e institucional en el espacio social, reformulando y recreando instituciones, fortaleciendo al estado y a su sistema de representación política ${ }^{47}$ Por ejemplo, bajo la nueva carta magna inició funciones la Corte Constitucional a la cual "se le confía la guarda de la integridad y supremacía de la Constitución”. Según el artículo $241^{\circ}$ de la Constitución Nacional, una de las principales funciones de este alto tribunal es decidir sobre la constitucionalidad de los decretos legislativos que dicte el gobierno o de los proyectos de ley que hayan sido objetados por el Gobierno como inconstitucionales. Además, se crea la figura de la Defensoría del Pueblo con el objeto de garantizar, promover, divulgar,

\footnotetext{
${ }^{44}$ En ese sentido, resulta interesante el trabajo de Irma Chumaceiro y María José Galucci que se interesa por el uso del concepto de democracia en los discursos de toma de posesión del poder de Hugo Chávez (1999 y 2007) y Álvaro Uribe Vélez (2002 y 2006), llegando a la conclusión de que el primero utiliza el concepto para definir la "democracia del pueblo" en oposición a las "elites minoritarias", mientras que el segundo define a la democracia reconociendo las divergencias políticas (Chumaceiro y Gallucci 2008). También se pueden advertir discursos fuertemente polarizantes en las tomas de posesión de Cristina Fernández como presidenta argentina (2007 y 2011). En ese sentido, ver: Costa, 2018.

${ }^{45}$ Para la definición de accountability horizontal remitirse a la nota al pie $\mathrm{n}^{\circ} 10$ del presente artículo.

${ }^{46}$ Guillermo O`Donnell, Disonancias: Críticas democráticas a la democracia, (Buenos Aires: Prometeo Libros, 2007), 100.

${ }^{47}$ Manuel Garretón, Los desafíos de la profundización democrática, (Santiago de Chile: Nueva serie Flacso 96, 1997), 40.
} 
defender y proteger los derechos humanos. Organismo que, por otro lado, adopta el estatus de imprescindible bajo el contexto del conflicto armado colombiano. También es creada la Fiscalía General de la Nación para, entre otras funciones, recolectar pruebas en el sistema penal para presentarla antes el juez durante el debido proceso.

Es decir, la reforma constitucional dio origen a instituciones estatales de "accountability asignadas" a los fines de enfrentar riesgos específicos de transgresión o corrupción intraestatal. Estas instituciones vinieron a complementar y/o reforzar las tareas emprendidas por las clásicas -e insuficientes- instituciones de Balance ejercidas por los poderes cuyas constituciones democráticas intentan balancear -ejecutivo, legislativo o judicial- ${ }^{48}$ No obstante, una mayor burocracia estatal no implica necesariamente una mejor calidad democrática. En primer lugar, porque estas instituciones deben funcionar coordinadamente para conformar una compleja red institucional que logre un punto de cierre o de llegada ante cada acción ilícita. En segundo lugar, deben tener la capacidad de invocar criterios profesionales antes que políticos partidarios para que sus acciones sean transparentes e imparciales. Finalmente, deben poseer un carácter continuo y proactivo en su accionar.

Cómo señalé en el capítulo anterior, desde comienzos de su gestión como presidente, Álvaro Uribe fortaleció los mecanismos de democracia directa e intentó transformar aquellos espacios institucionales creadores de políticas mediadas. Con esos fines impulsó un referendo de carácter popular tendiente a destacar la necesidad de transformar estas instituciones principalmente el Congreso- para acabar con la "corrupción y la politiquería". Sin embargo, si bien es cierto que algunos puntos del referendo estaban dirigidos a transparentar las actividades de la política ${ }^{49}$, no menos cierto es que determinados tópicos de la reforma debilitarían la eficacia de los mecanismos de control y rendición de cuentas debido a la privación de recursos a las instituciones encargadas de llevar adelante dichos mecanismos ${ }^{50}$. Todas ellas con la función de, entre otras cosas, controlar la gestión del Poder Ejecutivo y generar mecanismos de contrapeso entre los poderes del estado.

En ese sentido, los diversos poderes del Ejecutivo tales como: de nominación, de veto, de emisión de decretos ley, fiscales, de planificación y de emergencia; se vieron limitados en tiempo y espacio por las facultades otorgadas al Congreso a partir de la reforma de $1991^{51}$ Por este motivo, no es extraño que Álvaro Uribe haya impulsado una "contra reforma"

${ }^{48}$ Guillermo O’Donnell, Disonancias: Críticas democráticas a la democracia, (Buenos Aires: Prometeo Libros, 2007), 123 a 126.

${ }^{49}$ Por ejemplo, el punto 1 impedía que los funcionarios públicos que hayan sido condenados por delitos contra el patrimonio del estado, aspiren a cargos por elección popular y el punto 2 establecía que los miembros de asambleas, consejos y juntas administradoras locales voten públicamente (voto nominal) al aprobar leyes o disposiciones al interior de sus corporaciones.

${ }^{50}$ En ese sentido podemos destacar el punto 6 que suprimía las contralorías y personerías y el punto 10 que instaba a congelar por dos años, los gastos de funcionamiento de las entidades descentralizadas, autónomas, de naturaleza especial o única, que administren recursos públicos.

${ }^{51}$ María Gómez Dueñas y Julián Atilano Morales. 2014, Presidencialismo democrático en la actualidad: un acercamiento comparado entre los casos de México y Colombia, (México DF, Contextualizaciones Latinoamericanas -10-, 2014), 3. 
haciendo hincapié en modificar el diseño institucional legislativo que resultaba contrario a su forma personalista de ejercer el poder.

Lo interesante es que, a pesar de la gran aceptación por parte de la sociedad al liderazgo de Álvaro Uribe a partir del temor generado por la inseguridad que padecían los ciudadanos en Colombia, las limitaciones al ejercicio presidencial en Colombia se hicieron presentes. Sus pretendidas "reformas profundas" se vieron limitadas por decisiones institucionales - accountability horizontal-y de los propios votantes - accountability verticalque aprobaron una sola de las 15 reformas constitucionales propuestas por el gobierno del entonces presidente Uribe a finales de octubre de $2003^{52}$.

Por otra parte, a tan solo unos meses de asumir la primera presidencia, comienza a gestarse la idea de reformar la Constitución para habilitar a Álvaro Uribe a buscar la reelección de manera consecutiva. Esta búsqueda estuvo fundamentada en la alta adhesión popular que su gestión había alcanzado. Sin embargo, la propuesta reeleccionista tuvo que enfrentarse en el Congreso a las fuerzas políticas de la oposición e incluso a congresistas alineados con el Poder Ejecutivo. Esto ocurrió, en parte, por las características del sistema electoral colombiano cuya representación proporcional de los curules en el Congreso se dirimía por la lucha de facciones con intereses particulares. De esta manera, tras arduos procesos de negociación con congresistas de diversas agrupaciones, el gobierno obtuvo el número necesario para avanzar con el proyecto en ambas Cámaras. No obstante, existieron varias demandas ante la Corte Constitucional que planteaban desde vicios procedimentales hasta vicios de fondo. Finalmente, el proyecto de reelección es aprobado por el Congreso a fines de 2004.

Asimismo, los uribistas encuentran otro obstáculo institucional como consecuencia del pedido de inexequibilidad por parte del Procurador General a la Corte Constitucional "por vicios de trámite insubsanables presentados en su paso por el Congreso". Entre otras cosas, el Procurador señaló que corresponde a la Corte observar si el procedimiento llevado a cabo para efectuar la reforma constitucional "fue el resultado de un proceso democrático y no simplemente un acto de avasallamiento de las mayorías frente a las minorías" ${ }^{53}$ Luego de no dar lugar al pedido de inexequibilidad del Procurador, la Corte Constitucional autoriza a Álvaro Uribe a ir por la reelección presidencial.

Afortunadamente, Álvaro Uribe no tuvo allanado el camino para gobernar bajo un “decisionismo ilimitado", entre otras cosas, por la revisión sistemática de la Corte acerca de la validez constitucional de sus propuestas y el ingreso en el terreno de las negociaciones con los congresistas a la hora de lograr que aprueben sus iniciativas en el Congreso ${ }^{54}$ En ese sentido, una de las decisiones cruciales que tomó la Corte para el futuro de la democracia colombiana, fue la declaración de inexequibilidad al proyecto de referendo que pretendió

\footnotetext{
${ }^{52}$ La única reforma aprobada fue aquella que prohíbe a personas condenadas por delitos de corrupción a candidatearse para ocupar cargos electorales. Véase, ("Colombia: confirmada derrota en referendo" 2004).

${ }_{53}^{53}$ Procurador pide inexequibilidad de reelección presidencial, 2005. Procuraduría-Boletín 198.

${ }^{54}$ Carlos Pérez Múnera, La democracia delegativa. Revista Facultad de Derecho y Ciencias Políticas 37, (Medellín, 2007), 283 y 284.
} 
impulsar la segunda reelección presidencial de Álvaro Uribe. Está declaración de improcedencia procuró proteger y salvaguardar un régimen democrático de mediación institucional con lógica constitucional ${ }^{55}$ Esta limitación dio continuidad a lo que Stephen Holmes considera la esencia de la democracia: la alternación en el poder. Según el constitucionalista estadounidense "La existencia de límites claros a los gobiernos es una fuente de legitimidad distinta al miedo. Está basada más en la esperanza que en el temor. ${ }^{56}$

Ahora bien, me voy a permitir correrme parcialmente del escenario político electoral para hacer algunos comentarios respecto a la eficacia de las herramientas institucionales frente al fenómeno denominado "parapolítica". Cómo lo denunciara oportunamente la Corporación Nuevo Arco Iris, este fenómeno que atravesó la realidad política de Colombia implicó la penetración extendida de grupos armados ilegales en la vida política institucional del país. Incluso, en muchos casos se produjo una "cooptación invertida" donde los actores legales propiciaban los vínculos con organizaciones armadas ilegales para alcanzar beneficios políticos electorales. En ese sentido, en 2002 los congresistas que gozaron del apoyo del "narcoparamilitarismo" obtuvieron el 34\% de los curules y, cuatro años más tarde, un alto porcentaje de estos diputados fue reelegido formando parte de la segunda coalición del gobierno de Álvaro Uribe. ${ }^{57}$

Luego de las primeras investigaciones respecto a los vínculos entre funcionarios públicos y organizaciones armadas ilegales, comienzan a activarse mecanismos de institucionalidad estatal horizontal. En primer lugar, estas denuncias fueron acompañadas por los congresistas opositores -principalmente provenientes de las filas del Polo Democrático Alternativo- que acusaban a parte de la dirigencia uribista de hacer "parapolítica". Además, intervino la Unidad Nacional de Fiscalías para la Justicia y la Paz creada mediante la Ley $\mathrm{N}^{\circ}$ 975 de $2005^{58}$. Esta Unidad especial inició sus labores judiciales el 17 de agosto de 2006 al recibir la primera lista de postulados por parte del entonces Ministerio de Interior y de Justicia. Tanto la Fiscalía como la Corte Suprema de Justicia evidenciaron a través del cotejo de pruebas fílmicas, documentales y testimonios; la penetración de las organizaciones paramilitares en las instituciones estatales a nivel del Ejecutivo -alcaldías, gobernaciones- y a nivel del Legislativo -Senado, Cámara y Consejos Municipales-.

Estas investigaciones judiciales, en varios casos, se convirtieron en procesamientos y condenas a los culpables. En mayor o menor medida, los tribunales lograron echar luz sobre estas dinámicas relacionales poco democráticas -y desarrolladas a espaldas de la sociedad colombiana-, entre actores estatales legales y organizaciones ilegales. En ese sentido, a poco

\footnotetext{
55 Mauricio Uribe López, Colombia y Venezuela: ¿democracias delegativas o autoritarismos competitivos?, (Nueva Sociedad 227, 2010), 28.

${ }^{56}$ Stephen Holmes, La esencia de la democracia es la alternación en el poder, (Bogotá: El Espectador -13 de junio-, 2009).

${ }^{57}$ Claudia López Hernández, "La refundación de la patria, de la teoría a la evidencia". En Y refundaron la patria .... De cómo mafiosos y políticos reconfiguraron el estado colombiano, (Bogotá: Debate, 2010).

${ }^{58}$ Se recuerda que esta Ley constituyó el marco legal mediante el cual el gobierno nacional y los principales grupos paramilitares y de autodefensas finalizaron el proceso de negociación iniciado a finales del año 2002.
} 
de comenzar las investigaciones, la Corte ordenó la detención inmediata de aquellos congresistas vinculados al paramilitarismo quienes, en su gran mayoría, formaban parte de la coalición uribista de gobierno ${ }^{59}$ En 2010, los jueces y la Corte Suprema de Justicia habían dictado sentencia condenatoria sobre 25 congresistas de los 102 investigados por paramilitarismo. ${ }^{60}$

Durante el post-uribismo, la justicia continuó con los procesamientos y las condenas contra ex funcionarios de la gestión Uribe por nexos con el paramilitarismo y por tareas de inteligencia ilegal. Entre otros, se pueden mencionar los casos de los exdirectores del DAS (Departamento Administrativo de Seguridad) Jorge Noguera y María del Pilar Hurtado. Asimismo, en este grupo también se puede incluir al excongresista y primo del expresidente Álvaro Uribe, Mario Uribe, condenado por el máximo tribunal por nexos con el paramilitarismo. ${ }^{61}$

La respuesta del expresidente ante las acciones emprendidas por estas agencias estatales fue típicamente la de un líder que se muestra incómodo al tener que rendir cuentas horizontalmente a otras instituciones estatales. Es decir, estos mecanismos representaban para él, un estorbo indebido que interfería en su "gesta salvacionista". Para el expresidente, las causas que se investigaban -y aún se investigan- en su contra o sobre funcionarios y congresistas vinculados a su gobierno, forman parte de una "campaña de agravio" orquestada por opositores y miembros del Poder Judicial para "sacarlo del medio". Es decir, Álvaro Uribe apela a un instrumento extensamente utilizado por otros líderes políticos de la región, quienes, al verse cercados judicialmente, buscan blindarse a partir del apoyo popular de sus seguidores con el argumento de que son víctimas de una persecución política. Este escenario conspirativo se ve favorecido por la poca credibilidad que suscitan las instituciones judiciales en las sociedades latinoamericanas, las cuales no pocas veces, son penetradas e influidas por intereses particulares en desmedro del interés del bien común.

\section{Algunas reflexiones finales}

A lo largo del presente artículo pretendí aproximarme a las presidencias de Álvaro Uribe (2002-2010) a partir del marco teórico construido por el politólogo Guillermo O'Donnell para comprender a las "nuevas democracias latinoamericanas". Me parece importante aclarar que el nombre dado a este tipo de democracias -me refiero a la DD- es lo de menos. Lo fundamental es poder señalar ciertos aspectos peculiares presentes en este tipo de democracias más allá del nombre otorgado. Tampoco voy a poder señalar si en Colombia existió o no, bajo los gobiernos de Uribe, una DD. Desde mi punto de vista, la DD es un modelo teórico cerrado susceptible de ser utilizado como herramienta conceptual para explorar la política empírica. Pero de ningún modo se puede ser concluyente respecto a sí tal

\footnotetext{
${ }^{59}$ Los cinco congresistas capturados por sus nexos con los 'paras' son trasladados a la cárcel, 2007. Revista Semana, 15 de diciembre.

${ }^{60}$ Claudia López Hernández, "La refundación de la patria, de la teoría a la evidencia". En Y refundaron la patria ...: De cómo mafiosos y políticos reconfiguraron el estado colombiano, (Bogotá: Debate, 2010).

${ }^{61}$ Las batallas perdidas del uribismo en la justicia, 2015. El Tiempo, 18 de abril.
} 
o cual democracia es delegativa o no lo es. Desde esa óptica, lo importante fue advertir que ciertas dimensiones planteadas en el cuerpo teórico O'Donneleano estuvieron presentes en la democracia colombiana de comienzo de siglo y al mismo tiempo, identificar ciertos aspectos no coincidentes con las características típicas de este modelo.

Desde su forma de concebir y ejercer el poder, Álvaro Uribe presenta determinados trazos de un líder delegativo. En primer lugar, surge de una crisis aguda muy importante donde la población colombiana es invadida por una angustiosa inseguridad generalizada a raíz de la extensión del conflicto interno armado. Esto último se traducía en una mayor presencia territorial de los grupos armados ilegales y, en la sensación de que el estado colombiano había perdido la hegemonía del control y el uso de la fuerza en gran parte de su territorio. Este contexto propició una oportunidad para que Álvaro Uribe se presente como el "salvador de un país que está en peligro". Es decir, un líder político que vino a sacar a los colombianos de esa angustia e inseguridad en que se encontraban inmersos.

Además, la ciudadanía había perdido la confianza en las instituciones políticas representativas y demandaba la llegada de un poder personalista que pusiera fin a ese estado de caos generalizado. La crisis de representatividad de los partidos políticos tradicionales y su creciente atomización reforzó la idea de delegar el poder en un líder carismático. Esta falta de confianza en las instituciones representativas en particular y en las instituciones estatales en general, contribuyó a forjar un vínculo vertical directo entre Álvaro Uribe y sus seguidores, prescindiendo de instancias de política mediada. Ello se vio materializado en la creación de los Consejos Comunales o en las interpelaciones directas al pueblo a través de referendos que buscaban modificar el orden constitucional. Además, la sociedad colombiana comenzó a polarizarse en torno a la figura del entonces presidente. Esta dicotomía alrededor de una figura política había estado presente en la historia política de varios países de la región, pero, sin embargo, resultaba un fenómeno extraño en la historia de Colombia.

Por otro lado, a tono con un líder en una DD, Álvaro Uribe tuvo intenciones de debilitar ciertas instituciones de contralor creadas durante la reforma constitucional de 1991. En la reforma política enviada al Congreso en 2002, pretendió modificar la composición de las Cámaras, suprimir contralorías y congelar los recursos de instituciones estatales descentralizadas. Asimismo, mostró su malestar hacia las instituciones judiciales que investigaron -e investigan- tanto a su persona como a dirigentes de su extrema confianza. Bajo su teoría conspirativa, creía que las causas judiciales respondían a una persecución política de sus rivales con complicidad de quienes eran miembros de estas agencias judiciales. Sin embargo, a diferencia de otros líderes regionales que utilizaron un discurso confrontativo durante la toma de posesión del poder, quien fuera presidente de Colombia desplegaba un tipo de discurso amplio e inclusivo. La invitación a los ciudadanos era para que se comprometan con el interés comunitario dejando de lado la apatía hacía la política, más allá de la orientación ideológica o partidaria.

La singularidad que presentaba Colombia respecto a otras realidades regionales era el aceptable funcionamiento de los mecanismos de accountability horizontal. En varios acontecimientos que repasamos a lo largo del capítulo 4, se observa que estos mecanismos 
funcionaban tejiendo una red de instituciones vinculadas, que permitieron vehiculizar el control y la rendición de cuentas desde el origen hasta un punto de cierre en los tribunales. Esto por los menos se observa en las denuncias por parapolítica que recaían sobre miembros de la coalición gobernante: comenzaron en investigaciones de organizaciones sociales, académicas u ONGs, luego pasaron a la órbita del Congreso para, finalmente, darle un punto de cierre en las distintas instituciones que forman parte del Poder Judicial. Lo interesante es observar que este recorrido donde interactúan varias agencias estatales como el Congreso, la Fiscalía General, la Defensoría, los jueces y la Corte Suprema de Justicia; se llevó a cabo en pleno auge popular del presidente Álvaro Uribe -fue reelegido en 2006 con el $62 \%$ de los votos y poseía una imagen positiva altísima-. Sin embargo, en un plazo de tiempo relativamente corto desde que comenzaron las investigaciones, decenas de funcionarios y congresistas fueron condenados por la justicia.

Esto último no implica que no hayan existido presiones sobre el Poder Judicial o una posible influencia de figuras políticas de renombre en la actuación de la justicia. Simplemente, es dable señalar que no se observa esa profunda debilidad en los mecanismos de accountability horizontal que caracteriza a las DD de mayor intensidad, donde existe muy poca disposición y capacidad por parte de la justicia para sancionar conductas que puedan significar actos ilícitos. Allí, los mecanismos de control y rendición de cuentas, esenciales en el funcionamiento de un régimen democrático representativo, son subordinados a los tiempos e intereses de los partidos políticos. Máxime cuando los acusados son miembros de un partido gobernante que goza de altos niveles de aceptación popular. En cambio, hemos podido notar que, en el caso de Colombia, varios funcionarios que formaban parte de la coalición gobernante -en pleno fervor popular por el líder- fueron condenados por los tribunales de justicia.

\section{Bibliografía}

Anderson, L. 2006. "The Authoritarian Executive? Horizontal and Vertical Accountability in Nicaragua's New Democracy”. Latin American politics and Society 48(2): 141-169.

Arias Trujillo, Ricardo. 2010. Historia contemporánea de Colombia. Bogotá: Ediciones Uniandes.

Aterhortúa, Adolfo. 2007. Las banderas del presidente Uribe. Medellín: La carreta.

Aterhortúa, Adolfo y Diana Rojas Rivera. 2009. "La política de consolidación de la seguridad democrática: balance 2006-2008”. Análisis político (66): 59-80.

Brown, A. 1999. "Russia and Democratization". Problems of Post-Communism 46 (5): 3-13. 
Cheresky, Isidoro. 2015. "El nuevo rostro de la democracia”. Buenos Aires: Fondo de Cultura Económica.

Chumaceiro, Irma y María Gallucci. 2008. "La noción de democracia en los discursos de toma de posesión de Hugo Chávez y Álvaro Uribe". Revista Internacional de $\begin{array}{lllll}\text { Lingüística } \quad \text { Iberoamericana, } & \text { Vol. } & 6 & \text { (2): }\end{array}$ https://jstor.org/stable/41678349?seq=9\#page_scan_tab_contents.

"Colombia: confirmada derrota en referendo". 2004. BBCMundo.com, 3 de enero, http://news.bbc.co.uk/hi/spanish/specials/2003/balance_2003/newsid_3364000/336 4751.stm.

Costa, Flavio. 2018. "Democracia delegativa de alta intensidad: Una mirada sobre el régimen político argentino del siglo XXI”. Ciencia Nueva. Revista de Historia y Política, Vol. 2 (1): 75-98. https://revistas.utp.edu.co/index.php/historia/article/view/16661/10801.

Croissant, A. 2003. "Legislative Powers, Veto Players, and the Emergence of Delegative Democracy: A Comparison of Presidentialism in the Philippines and South Korea". Democratization 10 (3): 68-98.

Duque Daza, Javier. 2014. "Partidos y partidismo. Los partidos políticos colombianos y su enraizamiento en la sociedad". Revista FACULTAD DE DERECHO Y CIENCIAS POLÍTICAS (120): 311-347.

"Declaración Universal de los Derechos Humanos: lista de artículos", ACNUR-Comité Español, último acceso 22 de junio de 2018, https://eacnur.org/blog/declaracionuniversal-los-derechos-humanos-lista-articulos/

“Discurso de posesión del presidente Álvaro Uribe Vélez”. 2002. El Tiempo, 8 de agosto, https://eltiempo.com/archivo/documento/MAM-1339914.

Emmerich, G. E. 2009. "Informe sobre la democracia en México", en Araucaria. Revista Iberoamericana de Filosofía, Política y Humanidades, $\mathrm{N}^{\circ} 21$. Primer semestre: 186225.

Garretón, Manuel. 1997. “Los desafíos de la profundización democrática”. Análisis y opiniones- Nueva serie Flacso (96): 33-40.

Gómez Dueñas, María y Julián Atilano Morales. 2014. "Presidencialismo democrático en la actualidad: un acercamiento comparado entre los casos de México y Colombia”. Contextualizaciones $\quad$ Latinoamericanas $\quad$ (10): https://contextualizacioneslatinoamericanas.com.mx. 
Guáqueta, Alexandra. 2003. "Dimensiones políticas y económicas del conflicto armado en Colombia: Anotaciones teóricas y empíricas”. Colombia Internacional (55): 19-36.

Gutiérrez Sanín, Francisco. 2004. "Ilegalidad y sistema político en Colombia: la agenda de Uribe Vélez”. Nueva Sociedad (192): 59-71.

Hale, H., M. Mcfaul, et al. 2004. "Putin and the 'Delegative Democracy' Trap: Evidence from Russia’s 2003-04 Elections”. Post-Soviet Affairs 20 (4): 285-339.

Holmes, Stephen. 2009. "La esencia de la democracia es la alternación en el poder". El Espectador, 13 de junio, https://elespectador.com/impreso/política/articuloimpreso145727-esencia-de democracia-alternacion-el-poder.

Iazzeta, Osvaldo. "La democracia delegativa y su cara estatal. Un abordaje del caso argentino". En Democracia delegativa, coordinado por Guillermo O’Donnell, Osvaldo Iazzeta y Hugo Quiroga, 79-114. Buenos Aires: Prometeo Libros, 2011.

Ibañez, Ana y Andrea Velásquez. "El impacto del desplazamiento forzoso en Colombia: condiciones socioeconómicas de la población desplazada, vinculación a los mercados laborales y políticas públicas”. CEPAL-Serie Políticas sociales (145).

“Informe Latinobarómetro 2001”, Latinobarómetro, último acceso 29 de junio de 2018, https://latinobarometro.org/LATBD_latinobarometro_Informe_2001.

Ippolito-O'Donnell, Gabriela. "Visiones ciudadanas en torno de la democracia delegativa: Argentina y Brasil". En Democracia delegativa, coordinado por Guillermo O’Donnell, Osvaldo Iazzeta y Hugo Quiroga, 53-78. Buenos Aires: Prometeo Libros, 2011.

Kubicek, P. 1994. "Delegative Democracy in Russia and Ukraine". Communist and PostCommunist Studies 27 (4): 423-441.

Kubicek, P. 1998. "Authoritarianism in Central Asia: curse or cure?" en Third World Quaterly (19) 1: 29-43.

Kubicek, P. 2000. Unbriken Ties. The State, Interest Associations and Corporativism in PosSoviet Ukraine. Michigan: Michigan University Press.

Lair, Eric. 2000. “Colombia: Una guerra contra los civiles”. Colombia Internacional (49-50): 135-147).

"Las batallas perdidas del uribismo en la justicia", 2015. El Tiempo, 18 de abril, http://eltiempo.com/archivo/documento/CMS-15593157. 
Leal Buitrago, Francisco. 1988. "Democracía oligárquica y rearticulación de la sociedad civil: El caso colombiano". Colombia Pensamiento Iberoamericano: Revista de Economía Política (14).

Leal Buitrago, Francisco. 2006. “La política de seguridad democrática 2002-2005”. Análisis político (57): 3-30.

"Los cinco congresistas capturados por sus nexos con los 'paras' son trasladados a la cárcel", 2007. Revista Semana, 15 de diciembre, https://semana.com/on-line/articulo/loscinco-congresistas-capturados-nexos-paras-trasladados cárcel/83498-3.

"Los consejos comunales, la mejor vitrina que tuvo Uribe”, 2010. El país.com.co, 4 de julio, http://elpais.com.co/colombia/los-consejos-comunales-la-mejor-vitrina-que-tuvouribe.html.

López Hernández, Claudia. 2010. "La refundación de la patria, de la teoría a la evidencia”. En Y refundaron la patria...: De cómo mafiosos y políticos reconfiguraron el estado colombiano, editado por Claudia López Hernández. Bogotá: Debate.

Mejía Acosta, Andrés. “¿Revolución o delegación ciudadana? Democracia, gobierno y rendición de cuentas en Ecuador". En Democracia delegativa, coordinado por Guillermo O’Donnell, Osvaldo Iazzeta y Hugo Quiroga, 139-157. Buenos Aires: Prometeo Libros, 2011.

O'Donnell, Guillermo, Philippe Schmitter y Laurence Whitehead (ed.). 1986. Transitions from Authoritrian Rule: Prospects for democracy. Baltimore/London: University Press, 1986.

O'Donnell, Guillermo. 1992. “¿Democracia Delegativa?”. Cuadernos del CLAEH 17, n. º 61.

O'Donnell, Guillermo. 1993. “Acerca del estado, la democratización y algunos problemas conceptuales: Una perspectiva latinoamericana con referencia a países poscomunistas". Desarrollo Económico (130): 163-184. http://www.jstor.org/stable/3467251.

O'Donnell, Guillermo. 1998. “Accountability horizontal”. Estudios Políticos, cuarta época, (19): 9-46. http://dx.doi.org/10.22201/fcpys.24484903e.1998.19.

O'Donnell, Guillermo. 2007. Disonancias: Críticas democráticas a la democracia. Buenos Aires: Prometeo Libros.

O’Donnel, Guillermo. 2010. Democracia, agencia y estado. Buenos Aires: Prometeo Libros, 2010.

O’Donnell, Guillermo. 2011. "Nuevas reflexiones acerca de la democracia delegativa (DD)". En Democracia delegativa, coordinado por Guillermo O’Donnell, Osvaldo Iazzeta y Hugo Quiroga, 19-32. Buenos Aires: Prometeo Libros. 
Ollier, María. "Centralidad presidencial y debilidad institucional en las democracias delegativas". En Democracia delegativa, coordinado por Guillermo O’Donnell, Osvaldo Iazzeta y Hugo Quiroga, 115-137. Buenos Aires: Prometeo Libros, 2011.

Olvera, Alberto. “¿Existe la democracia delegativa en México? Notas sobre el régimen político, la transición a la democracia y la rendición de cuentas en los gobiernos subnacionales”. En Democracia delegativa, coordinado por Guillermo O’Donnell, Osvaldo Iazzeta y Hugo Quiroga, 161-198. Buenos Aires: Prometeo Libros, 2011.

Orjuela Escobar, Luis. 2000. "La debilidad del estado colombiano en tiempos del neoliberalismo y el conflicto armado". Colombia Internacional (49-50): 103-116.

Palacios, Marco y Frank Safford. 2002. Historia de Colombia: País fragmentado, sociedad dividida. Bogotá: Ediciones Uniandes.

Pérez Múnera, Carlos. "La democracia delegativa". Revista Facultad de Derecho y Ciencias Políticas 37, n. ${ }^{\circ} 106$ (2007): 263-289.

Pizarro Leongómez, Eduardo. 2002. "La Atomización Partidista en Colombia: el fenómeno de las Micro-empresas electorales". Kellog Intitute (292).

"Procurador pide inexequibilidad de reelección presidencial". 2005. Procuraduría-Boletín 198, último acceso 4 de julio de 2018, https://procuraduria.gov.co/html/noticias_2005/noticias_198.htm.

Quiroga, Hugo. "Parecidos de familia. La democracia delegativa y el decisionismo democrático". En Democracia delegativa, coordinado por Guillermo O’Donnell, Osvaldo Iazzeta y Hugo Quiroga, 35-52. Buenos Aires: Prometeo Libros, 2011.

Rosanvallon, Pierre. 2015. El buen gobierno. Buenos Aires: Ediciones Manantial.

Sánchez, José Antonio. 2002. "Este es el referendo de Uribe”. El tiempo, 6 de agosto, http://eltiempo.com/archivo/documento/MAM-1376229.

Shevtsova, L. 1999. Yeltsin's Russia. Myths and Reality. Washington DC: Carnegie Endowment for International Peace.

Tsygankov, A. 1998. "Manifestations of delegative democracy in Russian local politics: What does it mean for the future of Russia", Communist-Post-Communist Studies; 31 (4): 329-345.

Uribe López, Mauricio. “Colombia y Venezuela: ¿democracias delegativas o autoritarismos competitivos?’. Nueva Sociedad 227 (2010): 20-30. 
Vargas Velásquez, Alejo. 2004. "El gobierno de Álvaro Uribe: proyecto y resultados”. Nueva Sociedad (192): 85-97.

Walker, L. D. 2009. "Delegative Democratic Attitudes and Institucional Support in Central América". Comparative Political Studies 42 (10): 83-105.

“'Yidispolítica', el escándalo que nos dejó la reelección de Uribe”. 2015. El Tiempo, 15 de abril, http://eltiempo.com/archivo/documento/CMS-15575795. 